\title{
Diagnóstico ambiental da microbacia do Córrego das Areias como contribuição para a gestão dos recursos hídricos amazônicos
}

\author{
Aline dos Santos Betiolo ${ }^{1 *}$ (D), Nara Luísa Reis de Andrade ${ }^{2}$ (D) \\ 1 Programa de Pós-Graduação em Gestão e Regulação de Recursos Hídricos, Universidade Federal de Rondônia, \\ Campus Ji-Paraná, Rua Amazonas, 351, Bairro Jardim dos Migrantes - Ji-Paraná/RO - 76900-726 \\ 2 Mestrado Profissional em Gestão e Regulação de Recursos Hídricos, Universidade Federal de Rondônia, Campus Ji- \\ Paraná, Rua Amazonas, 351, Bairro Jardim dos Migrantes - Ji-Paraná/RO - 76900-726 \\ *Autora para correspondência: aline_straub7@hotmail.com
}

Recebido em 11 de fevereiro de 2021.

Aceito em 12 de abril de 2021.

Publicado em 15 de abril de 2021.

Resumo - Em busca de instrumentos que auxiliem o poder público na tomada de decisão e gestão das águas, o diagnóstico da bacia é de fundamental importância, expondo as pressões, os potenciais, conflitos existentes, bem como os usos estabelecidos na bacia. O presente trabalho tem como objetivo apresentar o diagnóstico ambiental da microbacia do Córrego das Areias, localizada no estado de Rondônia, região amazônica. Para tal avaliou-se o uso e ocupação do solo entre 2008 e 2019, foram realizadas coletas e análises de parâmetros físico-químico da água para os diferentes períodos sazonais. In loco, foi obtido o grau de preservação das nascentes utilizando parâmetros macroscópicos. Os resultados evidenciaram um incremento de $21,71 \%$ no desmatamento ao longo do período, bem como um aumento das áreas destinadas a agropecuária. Em relação às análises de qualidade de água as maiores concentrações encontradas foram no período de transição seca/cheia, porém dentro dos valores estabelecidos pela CONAMA $\mathrm{n}^{\circ} 357 / 2005$ para rios de classe 2 . Entretanto nenhuma das nascentes avaliadas apresentou grau de preservação "bom" ou "ótimo". Neste âmbito, medidas de gestão que mitiguem os impactos ambientais devem ser introduzidas na área de estudo, como a recuperação de nascentes, visando o aumento da qualidade dos recursos hídricos da bacia.

Palavras-chave: Impactos ambientais. Qualidade de água. Grau de preservação de nascentes. Instrumentos de gestão.

\section{Environmental diagnosis of the Córrego das Areias microbasin as a contribution to the management of Amazonian water resources}

Abstract - In search of instruments that help the public power in decision-making and water
management, the basin diagnosis is of fundamental importance, exposing the pressures, the
potentials, existing conflicts, as well as the uses established in the watershed. This paper aims
to present the environmental diagnosis of the "Córrego das Areias" microbasin, located in the
state of Rondônia, northern Brazil, in the Amazon region. To this end, land use and occupation
between 2008 and 2019 were evaluated, collections and analyzes of physical-chemical parameters
of water were performed for different seasonal periods. The springs' preservation degree 
was obtained using macroscopic parameters. The results evidenced an increase of $21.71 \%$ in deforestation throughout that period, as well as an increase in areas destined to cattle raising and agriculture. Regarding water quality analyzes, the highest concentrations found were in the dry/full transition period, but within the values established in CONAMA n³57/2005 for class 2 rivers. However, none of the evaluated springs showed a "good" or "excellent" preservation degree. In this context, management measures for mitigating environmental impacts must be introduced in the studied area, such as the recovery of the springs, in order to increase the quality of water resources in the microbasin.

Keywords: Environmental impacts. Water quality. Degree of preservation of springs. Management instruments.

\section{Diagnóstico ambiental de la microcuenca del Córrego das Areias como contribución a la gestión de los recursos hídricos amazónicos}

Resumen - En busca de instrumentos que ayuden a las autoridades públicas en la toma de decisiones y la gestión del agua, el diagnóstico de cuenca es de fundamental importancia, exponiendo las presiones, potenciales, conflictos existentes, así como los usos establecidos en la cuenca. El presente trabajo tiene como objetivo presentar el diagnóstico ambiental de la microcuenca del "Córrego das Areias", ubicada en el estado de Rondônia, en la región amazónica. Para ello se evaluó el uso y ocupación del suelo entre 2008 y 2019, se realizaron recolecciones y análisis de parámetros físico-químicos del agua para los diferentes períodos estacionales. Se obtuvo el grado de conservación de los manantiales in loco mediante parámetros macroscópicos. Los resultados mostraron un aumento del $21,71 \%$ en la deforestación durante el período, así como un aumento en las áreas destinadas a la agricultura y la ganadería. En cuanto a los análisis de la calidad del agua, las concentraciones más altas encontradas fueron en el período de transición seco / pleno, pero dentro de los valores establecidos por CONAMA n 357/2005 para ríos clase 2. Sin embargo, ninguno de los manantiales evaluados tuvo un grado de preservación "bueno" o "excelente". En este contexto, se deben introducir en el área de estudio medidas de gestión que mitiguen los impactos ambientales, como la recuperación de manantiales, con el objetivo de incrementar la calidad de los recursos hídricos de la cuenca.

Palabras Clave: Impactos ambientales. Calidad del agua. Grado de conservación de manantiales. Herramientas de gestión.

\section{Introdução}

A utilização dos recursos hídricos de forma consciente e equilibrada é de fundamental importância para o bem-estar ambiental, social e econômico. As alterações nos diferentes componentes do ambiente, como o relevo, o solo e a cobertura vegetal, podem resultar no comprometimento da qualidade da água e da funcionalidade do sistema, alterando o seu estado de equilíbrio dinâmico (Franco et al. 2012), o que pode comprometer serviços ecossistêmicos valiosos, como a disponibilidade de água (Cunha et al. 2016).

Nesse contexto, em busca de instrumentos que possam servir como subsídio para o poder público na tomada de decisão e formulação de políticas públicas para a gestão dos recursos hídricos, torna-se fundamental realizar o diagnóstico ambiental da bacia hidrográfica, considerada como 
unidade de gestão para a implementação da Política Nacional de Recursos Hídricos, instituída pela Lei no 9.433/1997, que estabelece como diretriz a articulação da gestão de recursos hídricos com a do uso do solo (Brasil 1997). Deste modo, o diagnóstico consiste na identificação, caracterização e mapeamento dos recursos naturais, bem como as intervenções antrópicas e impactos gerados, sendo uma ferramenta que contribui para desenvolvimento de práticas de manejo, conservação e revitalização de ambientes (Ferreira et al. 2015; Pinto et al. 2019), contribuindo para o fortalecimento do Sistema Nacional de Gerenciamento de Recursos hídricos (SINGREH).

Outro fator relevante no diagnóstico refere-se à qualidade da água, pois reflete o conjunto de ações e interações entre os diversos sistemas presentes na área estudada. De acordo com a ANA (2017), a qualidade da água superficial e subterrânea, sofre influência de diversos fatores naturais como por exemplo, o regime de chuvas, escoamento superficial, geologia e cobertura vegetal, assim como de impactos antrópicos, como o lançamento de efluentes, manejo dos solos, dentre outros usos estabelecidos na bacia.

Aliado a esse fato, o mapeamento e a caracterização das nascentes são essenciais para maximizar os benefícios ambientais advindos dos investimentos públicos e privados em sua conservação e recuperação (Ikematsu et al. 2017), visto que as nascentes são o ponto de partida para a conservação dos corpos hídricos e sofrem maiores impactos devido à sensibilidade frente às variações de uso do solo, sendo, portanto, essencial sua proteção (Marmontel et al. 2018; Javadi et al. 2019).

Nesse sentido, Rondônia apresenta graves problemas ocasionados pela supressão da vegetação nativa seguida pela conversão da floresta em áreas destinadas à agropecuária, o que pode vir a intensificar as mudanças climáticas e interferir no balanço de água, tendo em vista que as florestas da região amazônica são reguladores do clima (Gomes et al. 2015; Nascimentos et al. 2016; Rocha et al. 2017).

Da mesma forma, a microbacia do Córrego das Areias, pertencente a bacia do Rio Madeira, região amazônica, também apresenta tais problemas, refletindo na redução da vazão que em períodos secos pode contribuir para o surgimento de conflitos. Além disso, a microbacia possui grande importância sócio-ambiental e econômica para o município de Nova Brasilândia D’Oeste RO.

Diante do exposto, o presente trabalho tem como objetivo apresentar o diagnóstico ambiental da microbacia do Córrego das Areias, com base nos usos e ocupações do solo, o grau de preservação das nascentes e na qualidade de água na área de estudo, bem como, identificar os principais impactos ambientais presentes na microbacia, com o intuito de dar suporte à tomada de decisão por parte dos gestores e ao planejamento da gestão dos recursos hídricos, aliada à gestão do uso do solo, na área em estudo.

\section{Material e métodos}

A microbacia do Córrego das Areias está localizada no município de Nova Brasilândia D’Oeste - RO e compõe a sub-bacia do Rio Muqui (Figura 1), este por sua vez deságua no Rio Machado, também conhecido como Rio Ji-Paraná, pertencendo a Bacia Amazônica. A área da microbacia é de 9.805,90 hectares, composta majoritariamente por áreas rurais. 
Figura 1. Mapa de localização da Microbacia do Córrego das Areias em Rondônia, e pontos amostrados para análise de qualidade de água.

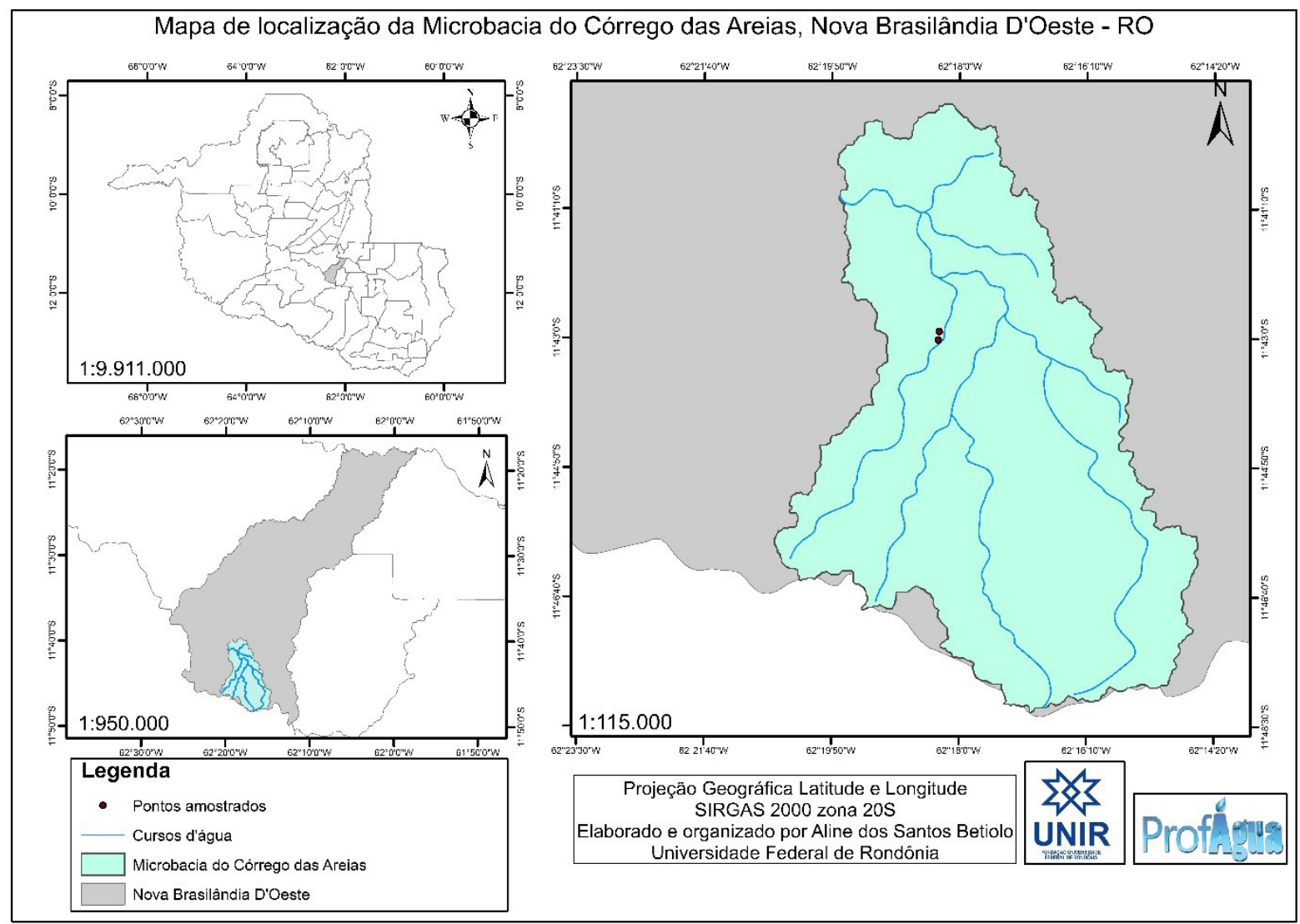

Para elaboração do diagnóstico da microbacia do Córrego das Areias, foram adotados alguns aspectos metodológicos, os quais serão descritos a seguir.

Para a avaliação temporal do uso e ocupação do solo foram utilizadas imagens de satélite do ano de 2008 e de 2019. Para o ano de 2008 foram utilizadas imagens do satélite Landsat 5, sensor Thematic Mapper - TM com a composição RGB através das bandas 3, 4 e 5, referente a órbita 231, ponto 68 com data do imageamento de 21/07/2008, bem como para o ano de 2019, foram utilizadas imagens do satélite Landsat 8, sensor Operational Terra Imager - OLI, composição RGB utilizando as bandas 4, 5 e 6, com resolução espacial de $30 \mathrm{mx} 30 \mathrm{~m}$, referente a órbita 231, ponto 68 e imageamento em 06/09/2019. As imagens foram obtidas por meio do banco de dados do Instituto Nacional de Pesquisas Espaciais - INPE (INPE 2019a).

Foram realizadas duas classificações, respectivamente para o ano de 2008 e 2019, utilizando a classificação supervisionada do Algoritmo de Máxima Verossimilhança - MAXVER, criando as classes de vegetação/mata, agropecuária, área urbanizada e água. A partir de tais dados, forma elaborados mapas para os anos 2008 e 2019, sendo 2019 o período mais atual e 2008 por apresentar um marco legal, o estabelecido no Código Florestal Lei $\mathrm{n}^{\circ} 12.651 / 2012$, para que desta maneira, possa-se verificar as mudanças ocorridas no uso e ocupação do solo durante o período abordado.

Os procedimentos de tratamento de informações e elaboração dos mapas foram realizados no software ArcGIS versão 10.7.1. 
Com o intuito de inferir sobre a qualidade de água da área em estudo, foram realizadas coletas e análises da água em dois pontos, sendo um a montante da Estação de Tratamento de Esgoto do município (P1) e outro a jusante (P2) (Figura 1).

Com a finalidade de verificar as variações temporais da qualidade de água, foram realizadas 04 coletas, abrangendo os diferentes períodos sazonais, sendo estes: seca (julho a setembro), seca/ cheia (outubro a dezembro), cheia (janeiro a março) e cheia/seca (abril a junho) (Gomes et al. 2015). A primeira coleta foi realizada no período de transição seca/cheia (nov/2018), a segunda coleta no período de cheia (mar/2019), a terceira coleta no período de transição cheia/seca (jun/2019) e a quarta e última coleta no período de seca (set/2019).

Os parâmetros analisados foram: $\mathrm{pH}$, temperatura, turbidez, oxigênio dissolvido, demanda bioquímica de oxigênio - DBO, fósforo total, nitrato, nitrito, nitrogênio amoniacal, sulfato e sulfeto (Quadro 1), e a determinação destes parâmetros foi realizada de acordo com o preconizado no Standard Methods for the Examination of Water and Wastewater (APHA 2005).

Quadro 1. Métodos utilizados para obtenção dos parâmetros físico-quimícos de qualidade da água na Microbacia do Córrego das Areias (RO).

\begin{tabular}{|l|l|l|}
\hline Parâmetro & $\begin{array}{l}\text { Método ou equipamento } \\
\text { utilizado }\end{array}$ & Fabricante do Equipamento utilizado \\
\hline Potencial Hidrogeniônico $(\mathbf{p H})$ & pHmetro & Marte MB-10P \\
\hline Temperatura & Termômetro digital & Incoterm Scan Temp ST-600 \\
\hline Turbidez & Turbidímetro & Hach 2100Q \\
\hline Oxigênio Dissolvido & Sonda multiparâmetro & Water Quality Meter AK88 \\
\hline DBO & Incubação 5 dias a $20^{\circ} \mathrm{C}$ & Fanem Estufa incubadora mod. 347 \\
\hline Fósforo Total & Espectrofotometria & Espectrofotômetro AJX-100 AJ Micronal \\
\hline Nitrato & Espectrofotometria & Espectrofotômetro AJX-100 AJ Micronal \\
\hline Nitrito & Espectrofotometria & Espectrofotômetro AJX-100 AJ Micronal \\
\hline Nitrogênio amoniacal & Espectrofotometria & Espectrofotômetro AJX-100 AJ Micronal \\
\hline Sulfato & Espectrofotometria & Espectrofotômetro AJX-100 AJ Micronal \\
\hline Sulfeto & Espectrofotometria & Espectrofotômetro AJX-100 AJ Micronal \\
\hline
\end{tabular}

Fonte: Organizado com base em Standard Methods for the Examination of Water and Wastewater (2005)

Para a obtenção do grau de preservação das nascentes, foram selecionadas 14 nascentes, sendo 3 urbanas e 11 rurais, através de imagens disponibilizadas pelo Google Earth. Os critérios para a escolha das nascentes foram: facilidade de acesso, presença de áreas desmatadas, além de visar contemplar nascentes de áreas urbanas e rurais e que estejam a montante do ponto de captação de água para o abastecimento público do município.

Nesse sentido, foi utilizada a metodologia adaptada e proposta por (Gomes et al. 2005), a qual utiliza parâmetros macroscópicos para avaliação do grau de preservação das nascentes. A metodologia consiste em, por meio de visitas in loco, realizar a coleta de dados, observar e verificar os parâmetros macroscópicos (Quadro 2), e atribuir pontos a cada parâmetro. Assim, os parâmetros 
são enquadrados em classe e atribuídos pontos para cada item, estabelecendo assim o grau de preservação. Observa-se que quanto mais degradada a nascente estiver, menor será a pontuação recebida (1) e quanto mais preservada maior será a pontuação (3).

Quadro 2. Parâmetros macroscópicos e atribuição de pontuação para cada aspecto.

\begin{tabular}{|l|l|l|l|}
\hline Parâmetros macroscópicos & Pontuação 1 & Pontuação 2 & Pontuação 3 \\
\hline Cor da água & Escura & Clara & Transparente \\
\hline Odor & Cheiro forte & Cheiro fraco & Sem cheiro \\
\hline Lixo ao redor & Muito & Pouco & Sem lixo \\
\hline Materiais flutuantes & Muito & Pouco & Sem materiais flutuantes \\
\hline Espumas & Muito & Pouco & Sem espumas \\
\hline Óleos & Muito & Pouco & Sem óleos \\
\hline Esgoto & Esgoto doméstico & Fluxo superficial & Sem esgoto \\
\hline Vegetação (preservação) & Alta degradação & Baixa degradação & Preservada \\
\hline Uso por animais & Presença & Apenas marcas & Não detectado \\
\hline Uso por humanos & Presença & Apenas marcas & Não detectado \\
\hline Proteção do local & Sem proteção & $\begin{array}{l}\text { Com proteção, mas } \\
\text { com acesso }\end{array}$ & Com proteção e sem acesso \\
\hline $\begin{array}{l}\text { Proximidade com residências } \\
\text { ou estabelecimentos }\end{array}$ & Menos de 50m & entre 50 a 100m & Mais de 100m \\
\hline Tipo de área de inserção & Ausente & Propriedade privada & Parques ou áreas protegidas \\
\hline
\end{tabular}

Fonte: Gomes et al. (2005)

Nota: ${ }^{*}$ a área a ser considerada para avaliação dos parâmetros foi a APP da nascente; ${ }^{* *}$ cercamento

Após a coleta dos dados e a atribuição de pontos, realizou-se a somatória dos pontos para cada nascente, classificando-as em cinco classes (Quadro 3).

Quadro 3. Classificação das nascentes de acordo com o Grau de Preservação.

\begin{tabular}{|c|c|c|}
\hline Classe & Grau de Preservação & Pontuação total \\
\hline A & Ótima & Entre 37 a 39 pontos \\
\hline B & Boa & Entre 34 a 36 pontos \\
\hline C & Razoável & Entre 31 a 33 pontos \\
\hline D & Ruim & Entre 28 a 30 pontos \\
\hline E & Péssima & Abaixo de 28 pontos \\
\hline
\end{tabular}

Fonte: Gomes et al. (2005) 
Em relação aos impactos ambientais, utilizou-se o sistema de indicadores Pressão-EstadoImpacto-Resposta (PEIR), para tal foram realizados levantamentos por meio da plataforma do IBGE (IBGE 2019) e in loco, com o intuito de verificar as principais atividades desenvolvidas no município, a fim de apontar os principais impactos na área de estudo, bem como sugerir medidas mitigadoras.

\section{Resultados e discussão}

\section{Análise temporal do uso e ocupação do solo}

A partir da análise do uso e ocupação do solo na área em estudo para o período de julho de 2008 (Figura 2), foram identificados usos do solo com atividade de agropecuária em 52,67\% da área da bacia, usos com vegetação/mata em $42,84 \%$ da área, 4,26\% área classificada como área urbana e $0,22 \%$ da área da bacia cobertas por água, este último abrangendo a atividade de piscicultura e corpos hídricos.

Figura 2. Mapa de uso e ocupação do solo na Microbacia do Córrego das Areias (RO) para o período de julho de 2008.

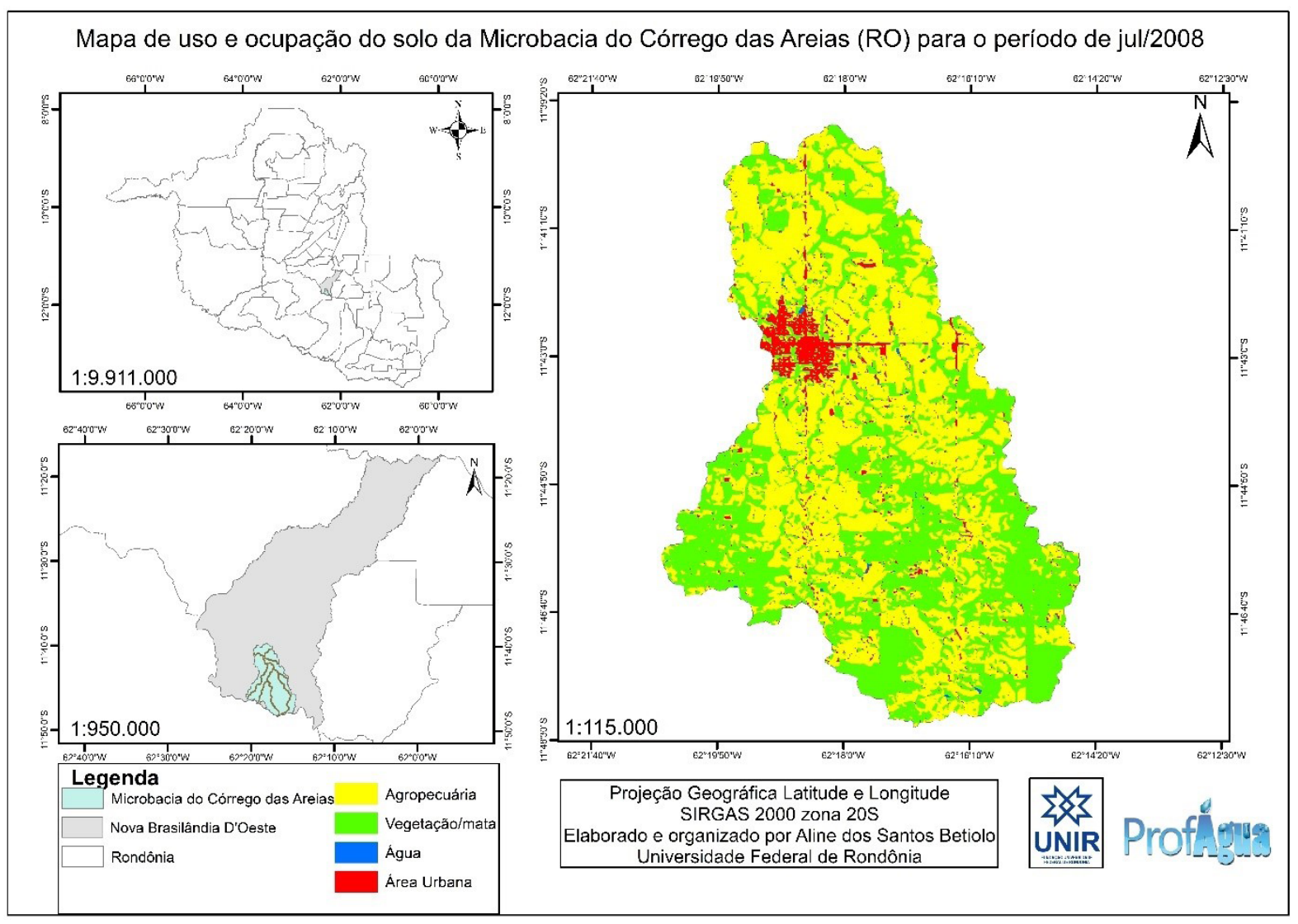

Desta maneira, evidencia-se a grande porção rural da microbacia, sendo 52,67\% da área da bacia destinado a atividade agropecuária, e 4,26\%, sendo compreendida por área urbana.

A este uso são relacionados impactos como o desmatamento, os quais propiciam a redução da infiltração de água no solo e, por conseguinte, o aumento do escoamento superficial, favorecendo o 
desenvolvimento dos processos de erosão do solo que conferem maior carga sedimentar aos cursos d'água (Watanabe et al. 2018). Ademais, a cobertura florestal desempenha um papel significativo na manutenção da água limpa, enquanto a agricultura e as áreas urbanas levam à degradação da qualidade da água (Mello et al. 2018).

Na bacia do Ribeirão Salitre, no triângulo mineiro, estudos de uso e ocupação do solo em 2017, revelaram que os maiores percentuais de áreas da bacia em estudo (38,5\%) eram destinados a agropecuária, apenas $17,8 \%$ das áreas eram compostas por mata/reflorestamento e $0,2 \%$ de área urbana (Guimarães et al. 2019). Padrão similar também foi encontrado na bacia do Ribeirão Vermelho (MG) com predomínio da agropecuária com 49,3\% e 19,35\% de fragmentos florestais, porém com um aumento da área urbana, sendo nesta bacia 21,45\% das áreas urbanizadas (Menezes et al. 2016) bem como na bacia do Rio dos Patos (GO) com $61 \%$ das áreas destinadas a agropecuária (Santos e Brito 2018) e na bacia do Rio Peixe-boi (PA) com 57,7\% do uso com agropecuária (Pereira et al. 2016), corroborando com os resultados encontrados neste estudo, evidenciando que a atividade agropecuária tem contribuído com o aumento do desmatamento, devido a conversão de áreas de florestas para tal atividade. No entanto, cabe ressaltar a grande heterogeneidade do uso e ocupação do solo em território brasileiro, especialmente em regiões distintas. Em contraste ao presente estudo, no município de Cuiabá (MT) o percentual de urbanização é elevado, das 8 microbacias estudadas, 4 delas apresentaram mais de 80\% de área urbanizada (Moraes et al. 2018).

No que tange ao uso e ocupação do solo para o período de setembro de 2019 (Figura 3) os maiores percentuais de áreas continuaram sendo destinados à atividade agropecuária $(75,18 \%)$, apresentando incremento expressivo de 22,51\% quando comparado aos resultados do ano de 2008.

Figura 3. Mapa de uso e ocupação do solo na Microbacia do Córrego das Areias (RO) para o período de setembro de 2019.

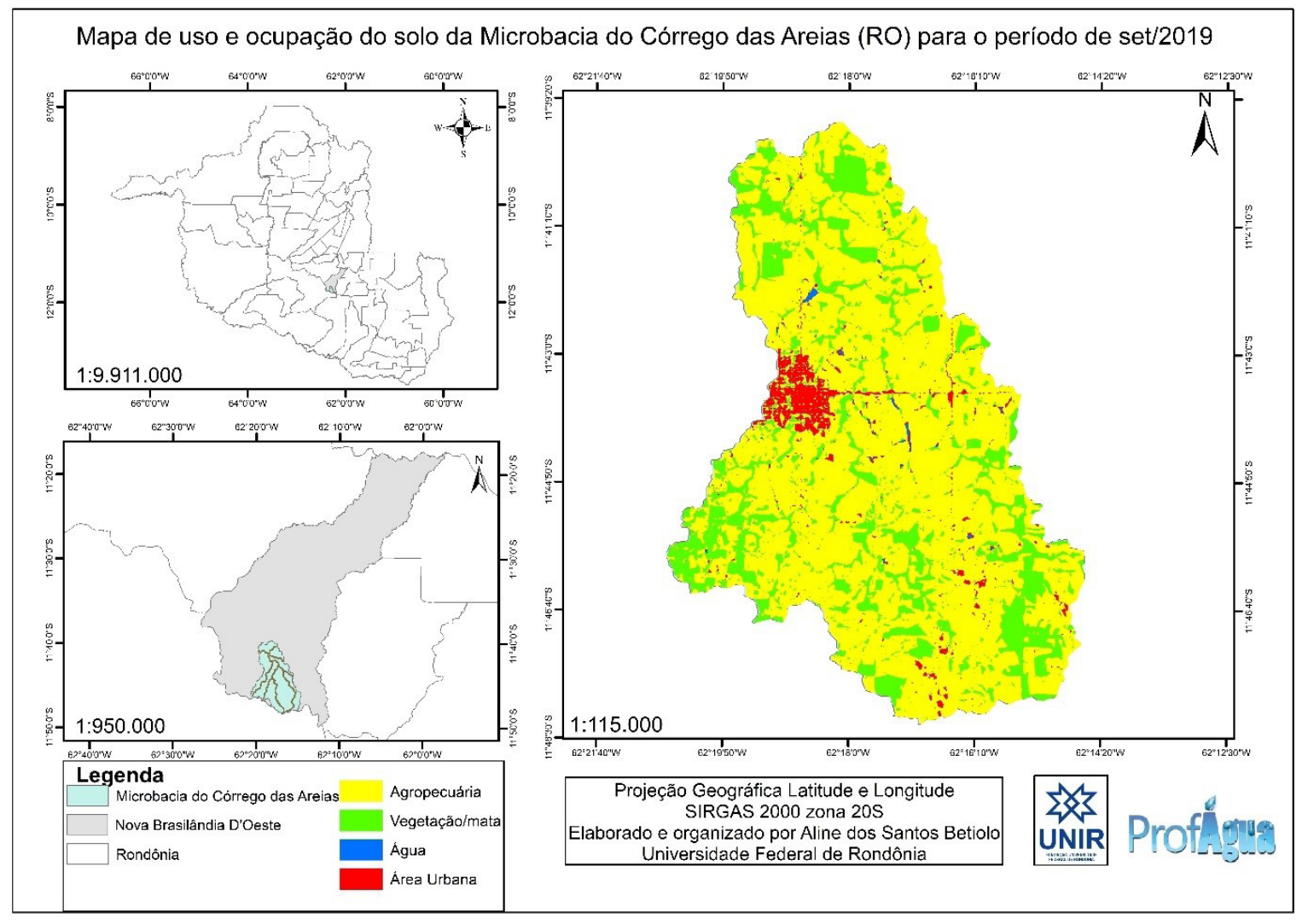


Os resultados evidenciam o desmatamento na área em estudo e corroboram o fato de que a atividade agropecuária contribui para o desmatamento, visto que com o aumento das áreas destinadas a agropecuária houve uma redução de $21,71 \%$ nas áreas de vegetação/mata comparado ao ano de 2008.

Vale destacar que no mês de agosto de 2019 foram registrados os maiores números de focos de incêndio desde 2010, sendo 28.440 focos de incêndio registrados no estado de Rondônia (INPE 2019b), evidenciando o período seco na região. Esses dados reforçam os resultados obtidos neste estudo, visto que os incêndios florestais são práticas utilizadas na região amazônica para reforma de pastagem e limpeza da área desmatada para ser utilizada pela atividade agropecuária.

Os resultados corroboram com os dados de desmatamento na região Amazônica, onde a taxa estimada de desmatamento foi de $9.762 \mathrm{~km}^{2}$ para o período de agosto de 2018 a julho de 2019, no qual o estado de Rondônia contribuiu com 12,75\%, o que equivale a $1.245 \mathrm{~km}^{2}$ (INPE $2019 \mathrm{~b}$ ). Semelhantemente a outros estudos na região amazônica de uso e ocupação do solo em áreas de APP, houve aumento no percentual de áreas desmatadas de 2008 a 2013 em Humaitá - AM (Machado et al. 2017), bem como em São Miguel do Guaporé - RO no período de 1990 a 2014 (Moura et al. 2017).

\section{Análise da qualidade de água}

Os resultados das análises físico-químicas realizadas para os diferentes períodos sazonais são apresentados os valores mínimos, médios e máximos de cada parâmetro para o período de coleta de nov/2018 a set/2019 (Tabela 1 ).

Tabela 1. Valores mínimos, médios e máximos para os parâmetros físico-químicos analisados na Microbacia do Córrego das Areias (RO).

\begin{tabular}{|c|c|c|c|}
\hline Parâmetros & Mínima & Média & Máxima \\
\hline DBO (mg.L $\left.{ }^{-1}\right)$ & 2,26 & 2,83 & 3,00 \\
\hline Fósforo total (mg.L-1) & 0,11 & 0,64 & 0,90 \\
\hline Nitrato $\left(\mathrm{mg} \cdot \mathrm{L}^{-1}\right)$ & 1,37 & 1,50 & 1,72 \\
\hline Nitrito (mg.L $\left.\mathrm{L}^{-1}\right)$ & 0,04 & 0,06 & 0,13 \\
\hline Nitrogênio amoniacal $\left(\mathrm{mg} \cdot \mathrm{L}^{-1}\right)$ & 1,80 & 2,36 & 3,00 \\
\hline OD $\left(\mathbf{m g} \cdot \mathrm{L}^{-1}\right)$ & 5,00 & 5,35 & 5,70 \\
\hline pH & 6,5 & 6,81 & 7,17 \\
\hline Sulfato total $\left(\mathrm{mg} . \mathrm{L}^{-1}\right)$ & 2,24 & 14,7 & 24,1 \\
\hline Sulfeto (mg.L $\mathrm{L}^{-1}$ ) & 0,03 & 0,05 & 0,22 \\
\hline Turbidez (UNT) & 20,1 & 31,5 & 57,4 \\
\hline Temperatura $\left({ }^{\circ} \mathrm{C}\right)$ & 14,5 & 19,0 & 22,0 \\
\hline
\end{tabular}

Em relação ao pH, este variou de 6,5 (ponto P1) no período de transição seca/cheia a 7,17 (ponto P1) no período de transição cheia/seca, apresentando desta forma, $\mathrm{pH}$ mais ácido nos 
períodos de transição seca/cheia e cheia e levemente alcalino no período de transição de cheia/seca e seca, comportamento similar do $\mathrm{pH}$ foi encontrado em um estudo de qualidade de água no Rio Mucuripe - PA, na região amazônica (Medeiros et al. 2017).

$\mathrm{O}$ pH e a turbidez são parâmetros influenciados pelo aporte de sedimentos, ou seja, pela lixiviação de materiais alóctones (Filho et al. 2016; Gholizadeh et al. 2016; Matias et al. 2018; Silva e Gouveia 2019). Em suma, quanto maior a quantidade de matéria orgânica a ser decomposta disponível no meio aquático, menor será o $\mathrm{pH}$, visto que devido a biodegradação desse material, são gerados ácidos orgânicos e gás carbônico (Oliveira et al. 2009).

Deste modo, para a turbidez, os maiores valores registrados foram no período de transição de seca/cheia, apresentando valores de 57,4 UNT (ponto P1) e 55,3 UNT (ponto P2). Corroborando, como já mencionado anteriormente, a questão do grande aporte de sedimentos que pode vir a ocorrer neste período de transição da seca para a cheia, carreando material do solo para dentro do corpo hídrico, como partículas de solo, excrementos de animais, fertilizantes e afins.

Nesse contexto, vale ressaltar que no período de seca, o aporte de sedimentos nos cursos d'água diminui. Deste modo, observa-se que os menores valores registrados de turbidez ocorreram no período de seca, apresentando valores de 23 UNT (ponto P1) e 20,1 UNT (ponto P2). Vale destacar que de acordo com Braga et al. (2005), a turbidez na água contribui para a diminuição da incidência luminosa no meio aquático, reduzindo a produção de oxigênio por meio da fotossíntese, principal responsável pela produção desse elemento no corpo hídrico.

Com relação à temperatura da água, esta variou com mínima registrada de $14,5{ }^{\circ} \mathrm{C}$ (ponto P2) no período de transição seca/cheia a $22{ }^{\circ} \mathrm{C}$ (ponto P1) no período de seca. Vale ressaltar que a temperatura exerce influência marcante na velocidade das reações químicas, nas atividades metabólicas dos organismos e na solubilidade de substâncias (Marsaro et al. 2017) o que influencia diretamente na disponibilidade de oxigênio dissolvido no meio aquático.

Em relação à concentração de oxigênio dissolvido - OD no corpo hídrico, esta variou de 5,0 mg.L $\mathrm{L}^{-1}$ a 5,7 mg.L $\mathrm{L}^{-1}$, sendo a concentração mínima registrada no período de transição de seca/cheia e a máxima no período de cheia e no período de seca, ambas no ponto P1 (Tabela 1).

Em praticamente todos os períodos amostrados o ponto P1 apresentou concentrações de OD maiores do que no ponto P2, com exceção do período de transição de seca/cheia onde o P1 apresentou concentração de 5,0 mg.L-1 e o ponto P2 5,2 mg.L-1 de OD, tais fatos podem estar associados a descarga de efluentes da ETE, e assim ocorrer um consumo de OD para mineralização da matéria orgânica proveniente no meio aquoso.

Segundo Pereira (2016), o oxigênio dissolvido é considerado um dos parâmetros mais significativos para expressar a qualidade de um ambiente aquático, necessitando de concentrações mínimas de OD de 2 mg.L-1 a 5 mg.L-1, para que sejam mantidas as condições básicas para os organismos aquáticos aeróbios sobreviverem, ressalta ainda que no que se refere aos peixes, estes necessitam de concentrações mínimas de 4 mg.L-1.

Concentrações máximas de OD de 5,9 mg.L-1 foram encontradas em áreas com predominância do uso do solo com pastagens na região amazônica (Costa et al. 2017), valores similares também aos encontrados em córregos em Humaitá (AM) com máxima no período seco de 5,9 mg.L-1 (Oliveira et al. 2018). Observa-se que a máxima encontrada é similar a máxima encontrada neste estudo, 5,7 mg.L-1. 
Deste modo, os resultados evidenciam que mesmo com o aporte de sedimentos e efluentes para o corpo hídrico, o córrego ainda manteve as concentrações mínimas estabelecidas pela resolução CONAMA 357/2005 de 5 mg.L-1 de OD e os padrões necessários para a sobrevivência dos organismos aquáticos.

Outro parâmetro analisado foi a demanda bioquímica de oxigênio - DBO. A média encontrada para esse parâmetro foi de 2,83 mg.L-1, valores que podem ser considerados baixos, quando comparados ao máximo permitido pela CONAMA 357/2005 para rios de classe 2, de 5,0 mg.L1, bem como quando comparado as concentrações encontradas no Rio Amazonas (AP), que apresentou valores médios de 5,0 mg.L-1 no período menos chuvoso e de 2,0 mg.L-1 no período mais chuvoso (Damasceno et al. 2015).

Desta maneira, dado que a DBO se refere ao consumo de OD disponível no meio aquático pelas bactérias decompositoras no processo de mineralização da matéria orgânica, e baseado nas análises é possível afirmar que não há grande presença de matéria orgânica no corpo hídrico, uma vez que as concentrações de OD no meio aquático apresentaram padrões aceitáveis pela legislação CONAMA 357/2005 e a DBO seguiu padrão condizente.

No que tange aos resultados obtidos nas análises de nitrato, nitrito e nitrogênio amoniacal, as maiores concentrações foram registradas no período de transição seca/cheia (nov/2018), apresentaram valores de 1,72 mg.L-1 (P2), 0,13 mg.L-1 (P1 e P2) e 3,0 mg.L-1 (P2), respectivamente (Figura 4). Devido ao início das chuvas esse material pode ter sido carreado para o corpo hídrico, aumentando sua concentração, fato corroborado pelo mesmo comportamento da turbidez, principalmente pelo fato da área em estudo apresentar atividades de agricultura que podem contar com a adubação nitrogenada do solo, bem como os excrementos da criação de gado, gerados na atividade de pecuária, os quais também são fontes de nitrogênio.

Figura 4. Resultados das análises para os parâmetros fósforo total, nitrato, nitrito e nitrogênio amoniacal para os diferentes períodos sazonais na Microbacia do Córrego das Areias (RO). Nota: os resultados das análises de nitrito para os períodos de cheia, transição cheia/seca e seca, foram menores que 0,04 (mg.L-1).

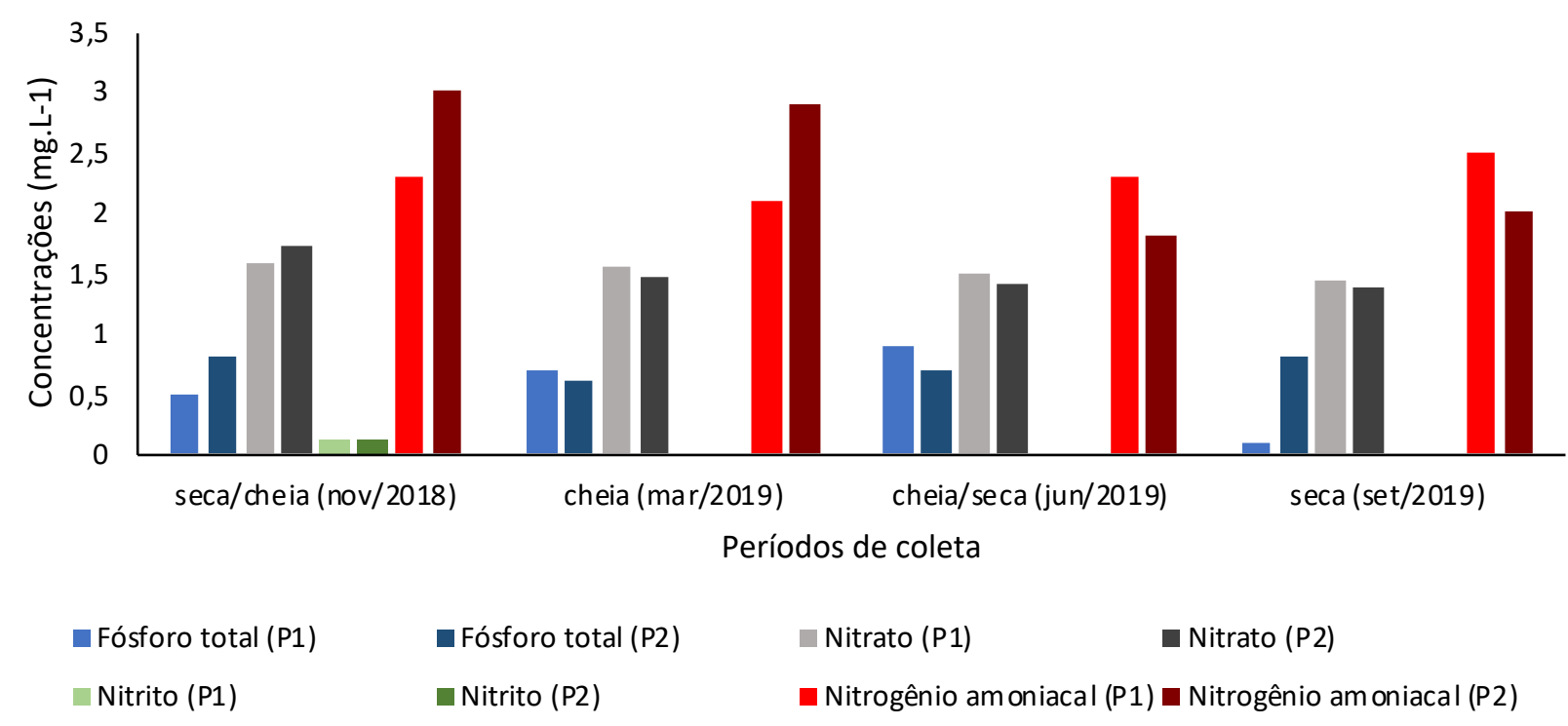

A concentração de fósforo total foi maior no período de transição de cheia/seca (jun/2019) com valor de $0,9 \mathrm{mg} . \mathrm{L}^{-1}(\mathrm{P} 1)$. Assim, como neste estudo, em rios amazônicos no Pará, também foram 
encontradas as maiores concentrações de fósforo de $0,09 \mathrm{mg} \cdot \mathrm{L}^{-1}$ no período de transição seca/cheia (Medeiros et al. 2017).

Um estudo realizado por Aguiar et al. (2014), analisando a qualidade da água de 24 microbacias hidrográficas, no Pará, os valores medianos foram maiores para fósforo total e nitrogênio amoniacal no período chuvoso em relação ao período de estiagem, nas áreas antropizadas, já os valores obtidos para nitrato e nitrito não apresentaram variação.

Butzke (2013), em seu estudo no Igarapé Pintado, Rondônia, encontrou maiores valores de fósforo total $\left(0,013 \mathrm{mg} . \mathrm{L}^{-1}\right)$ e nitrogênio amoniacal $\left(0,197 \mathrm{mg} . \mathrm{L}^{-1}\right)$ no período de seca o que segundo a autora tais concentrações podem estar associadas a lançamentos de efluentes recentes no local, bem como no período de seca há uma menor dispersão dos efluentes.

Em relação ao nitrato, Santos (2012) encontrou em sua pesquisa no Igarapé Dois de Abril (RO), região amazônica, concentrações de $2,33 \mathrm{mg} . \mathrm{L}^{-1}$ para o período de transição seca/cheia, valor este maior que os obtidos na presente pesquisa para o mesmo período, sendo eles respectivamente 1,58 mg.L.-1 (P1) 1,72 mg.L.-1 (P2).

Para nitrogênio amoniacal, foram encontrados valores máximos de 3,0 mg. $\mathrm{L}^{-1}$ e 2,9 mg. $\mathrm{L}^{-1}$, ambos no ponto P2, respectivamente para o período de seca/cheia e período de cheia, indicando presença de esgoto recente, o que pode ser atribuído aos lançamentos da ETE, visto que o ponto P2 apresentou valores maiores que o ponto $\mathrm{P} 1$. No entanto, mesmo com o aumento da concentração nestes períodos, os valores ainda permaneceram de acordo com o estabelecido na Resolução CONAMA 357/2005, para corpos hídricos de classe 2, pois de acordo com a referida resolução o valor máximo permitido é de $3,7 \mathrm{mg} / \mathrm{L} \mathrm{N}$, para $\mathrm{pH} \leq 7,5$, visto que o $\mathrm{pH}$ para o ponto $\mathrm{P} 2$ nos períodos supracitados estiveram em torno de 6,5. Vale ressaltar que concentrações elevadas de nitrogênio e fósforo no ambiente aquático podem causar graves problemas de eutrofização.

No que se refere aos parâmetros de sulfato total (Figura 5), a concentração mínima de sulfato total encontrada foi de $2,24 \mathrm{mg} . \mathrm{L}^{-1}$ no período de transição de seca/cheia e as maiores concentrações para este parâmetro foram registradas no ponto $\mathrm{P} 1$, no período de cheia $\left(24,14 \mathrm{mg} \cdot \mathrm{L}^{-1}\right)$ e no período de transição de cheia/seca $\left(22,2 \mathrm{mg} . \mathrm{L}^{-1}\right)$, valores estes bem abaixo do valor máximo que é permitido pela Resolução CONAMA n ${ }^{\circ} 357 / 2005$, de 250 mg.L.' ${ }^{-1}$.

Figura 5. Resultados das análises para o parâmetro sulfato para os diferentes períodos sazonais na Microbacia do Córrego das Areias (RO).

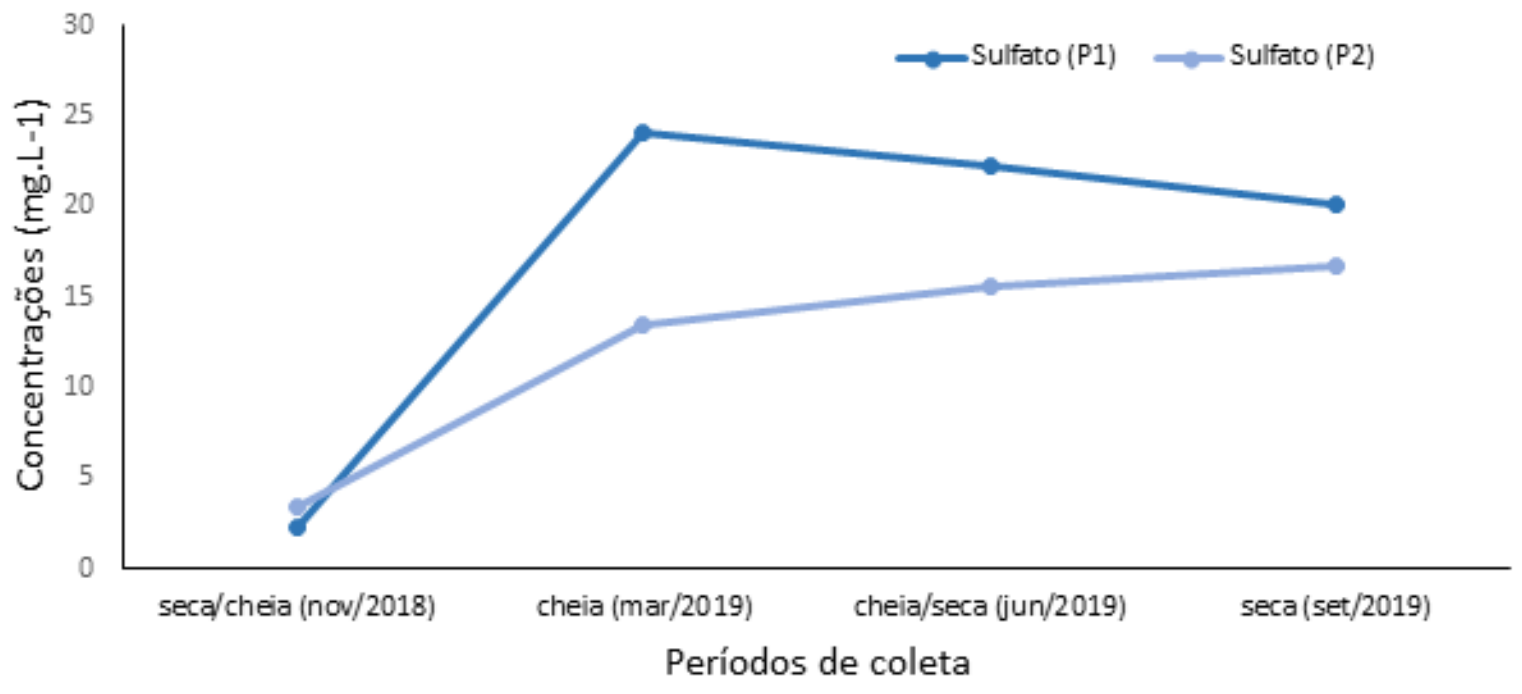


No entanto tais valores podem ser considerados elevados se comparados aos encontrados em lagoas em uma área de preservação do município de Ji-Paraná (RO) de 2,37 mg.L.-1 (Dias et al. 2019), o que pode indicar o lançamento de efluentes domésticos ou industriais, visto que o sulfato ocorre nas águas superficiais por meio das descargas de esgotos domésticos (por degradação de proteínas) e efluentes industriais (Torres et al. 2017).

Ainda, de acordo com as características do local como, curso d'água com pouca profundidade e alta evaporação, as concentrações de sulfatos geralmente são altas (Esteves 2011), características essas similares as da área em estudo.

Em relação às concentrações de sulfeto, os maiores valores foram obtidos no período de transição de seca/cheia, sendo no ponto P1 registrado o valor de $0,22 \mathrm{mg}$. $\mathrm{L}^{-1}$ e no ponto P2 a concentração de $0,21 \mathrm{mg} \cdot \mathrm{L}^{-1}$, nota-se que para este parâmetro as concentrações não demonstraram variação significativa de um ponto para outro.

\section{Análise do Grau de Preservação das Nascentes}

Com relação ao grau de preservação das nascentes, observa-se que 57\% das nascentes avaliadas apresentaram grau de preservação razoável, $29 \%$ ruim e $14 \%$ péssima, sendo que não foram encontradas nascentes com grau de preservação ótima ou boa (Figura 6).

Figura 6. Grau de preservação das nascentes da microbacia do Córrego das Areias (RO).
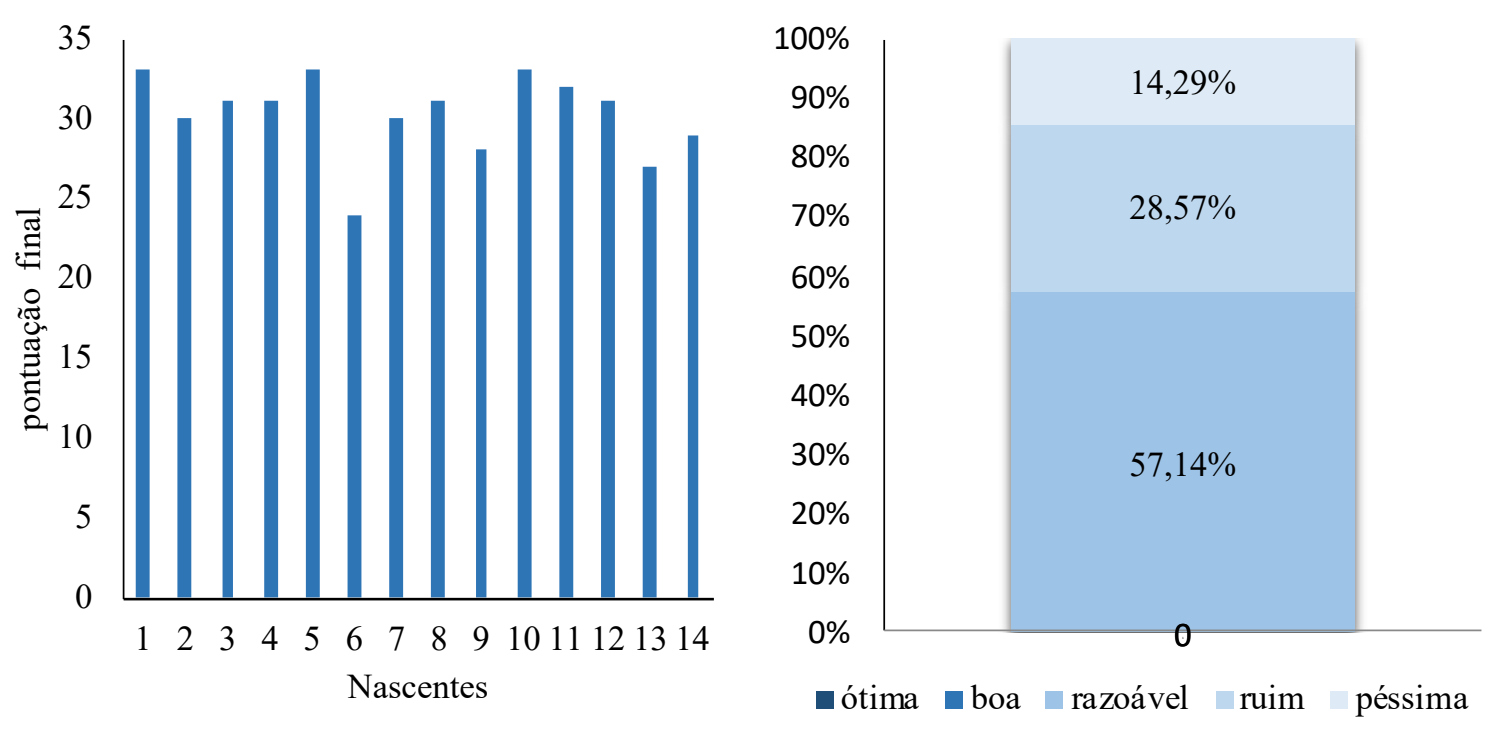

Em relação à vegetação (Figura 7), a maioria das nascentes avaliadas apresentou alta degradação (50\%), ou seja, pouca o quase nenhuma vegetação arbórea, onde a área de preservação permanente foi danificada, expondo a nascente a vários impactos ambientais. As nascentes que foram consideradas preservadas, ou seja, com sua APP preservada, no que tange a Lei Federal no $12.651 / 2012$, foram apenas $21,43 \%$ das nascentes. 
Figura 7. Grau de preservação das nascentes da Microbacia do Córrego das Areias (RO) em função da vegetação.

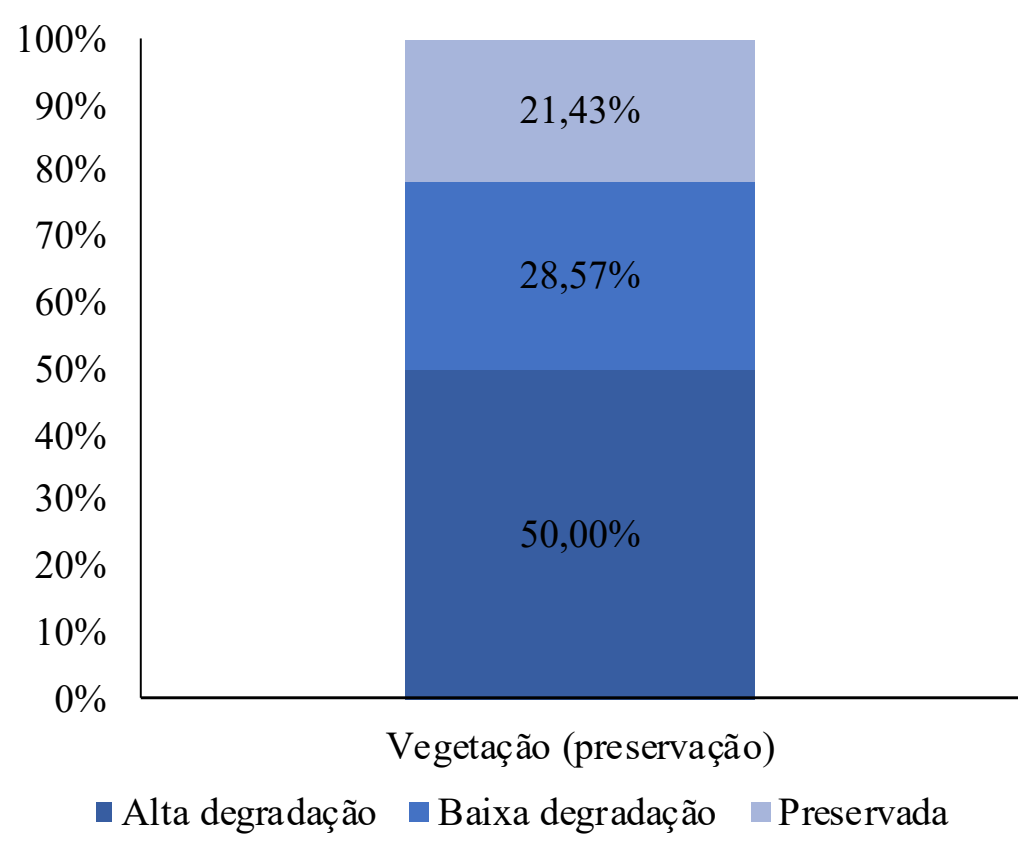

Em Goioerê (PR) 100\% das nove nascentes avaliadas apresentaram alguma irregularidade em relação à vegetação, a qual não atendia ao Código Florestal (Negri-Sakata e Kimura 2018), bem como em Rio Claro (SP) onde $72 \%$ das nascentes apresentaram alto nível de degradação (Pieroni et al. 2019).

Situação inversa foi encontrada nas nascentes do Córrego Grande em Rondonópolis (MT) com 65,71\% das nascentes avaliadas com excelente grau de preservação em relação a vegetação (Pessi et al. 2018).

Desta maneira, os resultados revelaram a exposição das nascentes em relação a remoção de vegetação, o que pode ser atribuído em grande parte a agropecuária, visto que vastas áreas foram desmatadas para a implantação dessa atividade, e em muitos casos não foram mantidas as APPs conforme preconiza a Lei Federal nº12.651/2012.

Outro parâmetro macroscópico analisado refere-se à proteção do entorno das nascentes, sejam elas, barreiras naturais ou artificiais, com o intuito de evitar, por exemplo, o pisoteio da vegetação, assim como que animais herbívoros se alimentem dessa vegetação. Dentre as nascentes avaliadas 78,57\% não dispõe de proteção, 7,14\% apresentaram proteção, porém tais proteções possibilitam o acesso, principalmente de animais, que podem utilizar as nascentes como fonte de água para dessedentação, e 14,29\% das nascentes dispõe de proteção onde não tem acesso a nascente (Figura 8). Ressalta-se que os casos de proteção sem acesso (14,29\%) foram registrados em áreas rurais, com presença de introdução de mudas, onde provavelmente o proprietário realizou o isolamento da área visando a sua recuperação. 
Figura 8. Grau de preservação das nascentes da Microbacia do Córrego das Areias (RO) em função da proteção (cercamento) e da presença de resíduos sólidos no entorno
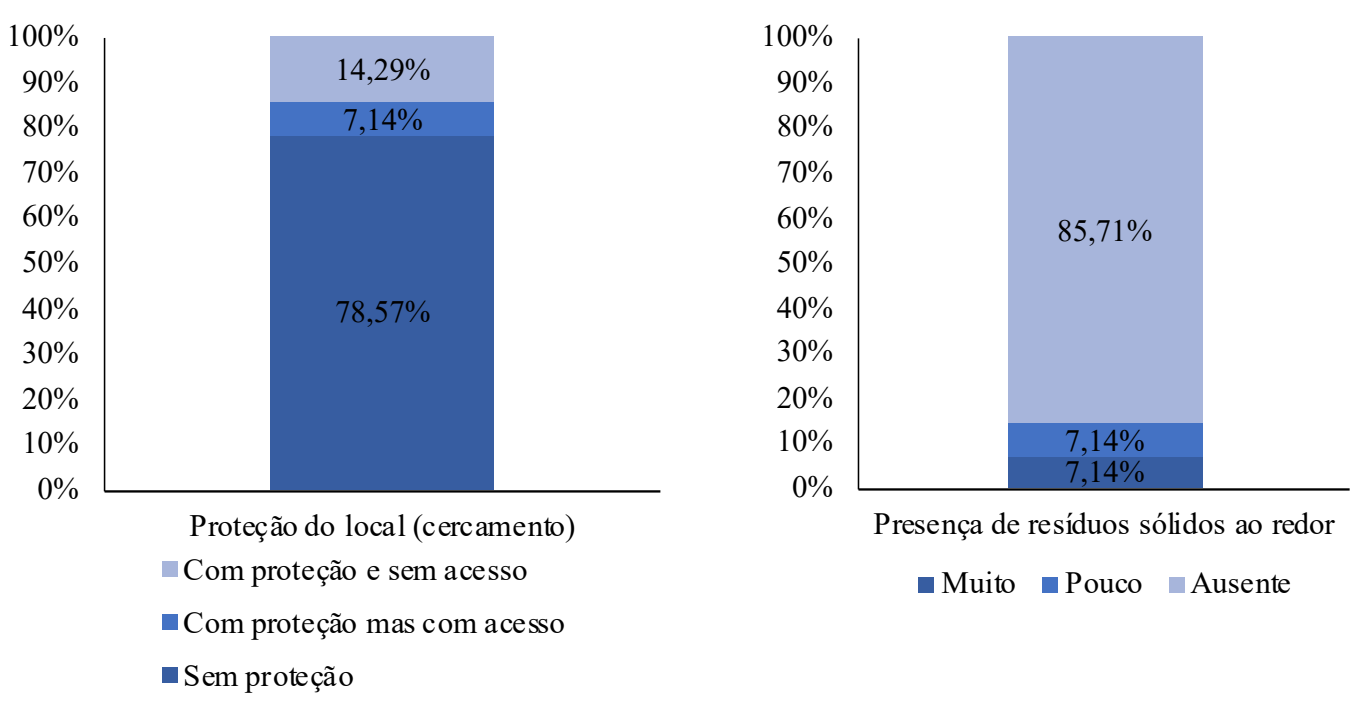

A proteção do entorno das nascentes em muitos casos é primordial para o desenvolvimento da vegetação e a recuperação da área, situação recorrente em várias regiões, como na região sul do Brasil, em Goioerê - PR, onde um estudo revelou que a proteção das nascentes foi insatisfatória deixando-as expostas (Negri-Sakata e Kimura 2018). Em Rio Claro (SP), 67\% das nascentes avaliadas não possuíam proteção (Pieroni et al. 2019).

No que se refere a presença de resíduos sólidos ao redor das nascentes, este apresentou padrão inverso ao da degradação da vegetação e de proteção das nascentes, sendo que em $85,71 \%$ das nascentes avaliadas não havia presença de resíduos sólidos (Figura 8), fator positivo, visto que a disposição inadequada de resíduos pode causar a contaminação dos corpos hídricos, consequentemente interferindo na qualidade de água da microbacia. Outros estudos também apresentaram padrão similar para este parâmetro, como na microbacia Ibitinga (SP) (Pieroni et al. 2019), e na bacia do Rio Paraim (PI) (Rocha et al. 2019).

Em nenhuma das nascentes avaliadas foi verificada a presença de esgoto e nem a presença de espumas, e apenas uma das nascentes apresentou odor. Fato que pode ser correlacionado com a proximidade de residências ou estabelecimentos, visto que $57,14 \%$ das nascentes estão a mais de 100 m de distância destes.

Em nascentes do Rio Paraim (PI) também não foram encontrados lançamentos de esgoto nas nascentes avaliadas, visto que $85,7 \%$ das nascentes estavam a mais de $100 \mathrm{~m}$ de residências (Rocha et al. 2019), corroborando com os resultados encontrados neste estudo.

Vale ressaltar que $78,57 \%$ das nascentes avaliadas estão localizadas em áreas de propriedade privada e nenhuma em parques ou áreas protegidas, o que poderia auxiliar a preservação destes sistemas, como corroborado pelo estudo das nascentes em Capão Bonito (SP), onde nenhuma das nascentes apresentou qualificação ruim ou péssima, sendo que $66 \%$ das nascentes avaliadas estavam dentro da área da unidade de conservação (Leal et al. 2017).

Os resultados evidenciam, segunda a metodologia utilizada, a precariedade do estado de preservação das nascentes, e a necessidade de revitalização das mesmas, com o intuito de manter a disponibilidade hídrica na microbacia. 


\section{Principais usos e impactos ambientais existentes na Microbacia do Córrego das Areias}

Os principais usos e impactos ambientais, assim como as sugestões de medidas para mitigar os impactos identificados na área em estudo (Figura 9).

A principal atividade é agropecuária, com destaque na agricultura com as produções de café, seguido por banana, maracujá e laranja, na pecuária para a criação de gado de corte e leiteiro e criação de tambaquis na piscicultura (IBGE 2019).

Figura 9. Principais usos, impactos ambientais e medidas mitigadoras, utilizando a metodologia PEIR, na microbacia do Córrego das Areias (RO), 2019

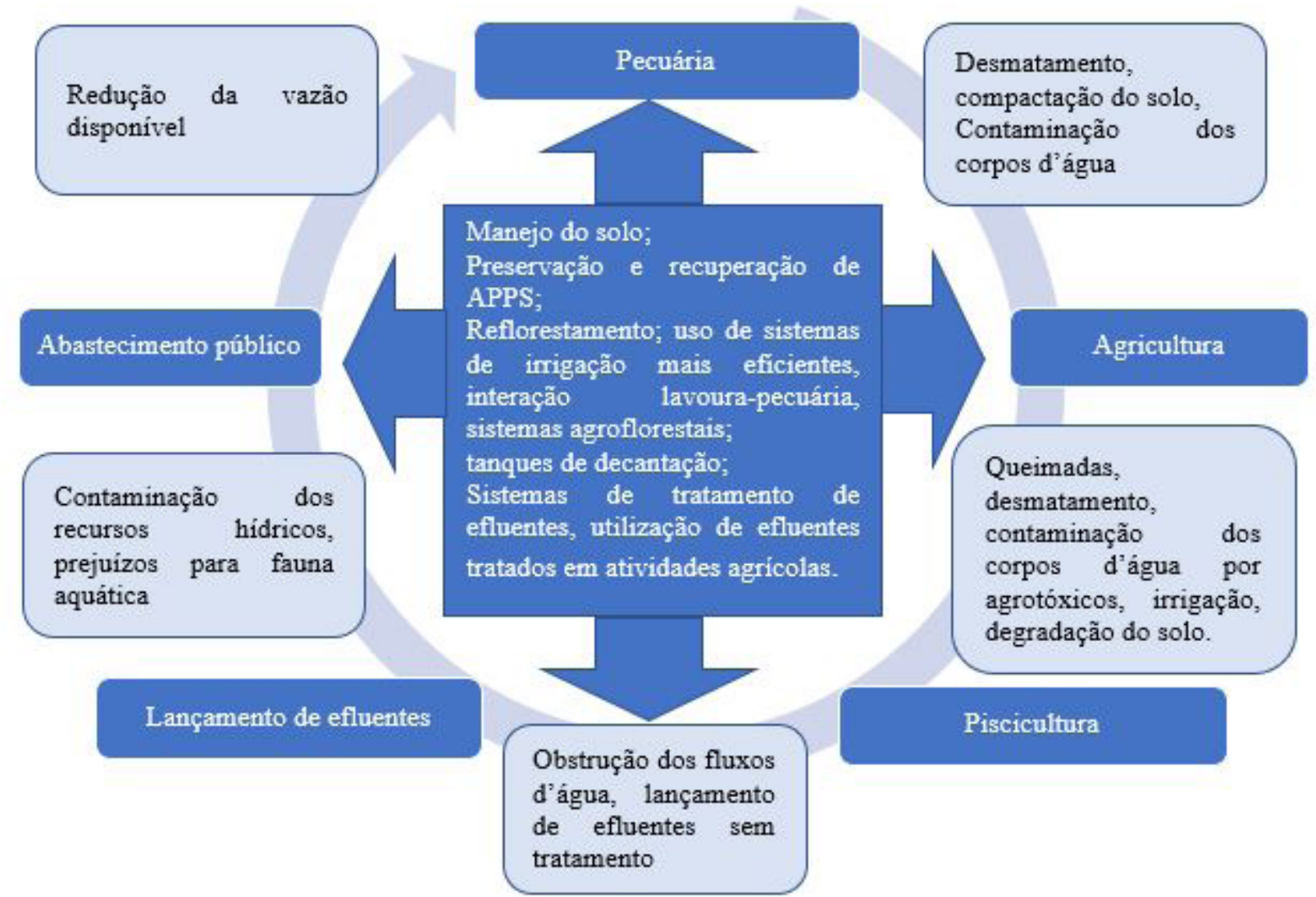

Nota: Balões em azul escuro=usos; balões em azul claro=impactos; balão central em azul escuro=medidas mitigadoras

Nesse sentido, observa-se que as atividades desenvolvidas na bacia, quando gerenciadas de maneira inadequada, podem acarretar inúmeros impactos ambientais, tais como desmatamento, empobrecimento do solo, contaminação dos recursos hídricos dentre outros.

Esses impactos são gerados a partir do modo como ocorre o uso e ocupação da terra, desconsiderando a dinâmica do meio físico, resultando na geração de riscos, quando da ocorrência de movimentos de massa, processos erosivos, enchentes, inundações e alagamentos (Santos et al. 2016).

Desta maneira, a exposição dos recursos hídricos, principalmente pela remoção da vegetação ciliar, tem causado o assoreamento dos cursos d'água na microbacia, depositando sedimentos de 
diversas origens no leito do rio, bem como a erosão das margens, visto que sem a referida vegetação esses sistemas ficam desprotegidos.

Deste modo, o estudo revelou a falta de articulação entre o uso e ocupação do solo com a gestão dos recursos hídricos, haja vista os índices de desmatamento na região e o aumento das áreas destinadas a agropecúaria, corroborado pelo baixo graus de preservação das nascentes da microbacia do Córrego das Areias obtido neste estudo, sendo um dos principais fatores a ausência de vegetação nas APPs.

Nesse sentido, a conversão das áreas de florestas em pastagem expõe o solo, refletindo diretamente nos níveis de infiltração de água no solo, uma vez que a floresta amortece o escoamento superficial, desempenhando uma importante função na manutenção da água, e deste modo, auxilia na recarga dos recursos hídricos (Mello et al. 2018; Silva et al. 2018; Watanabe et al. 2018). Assim, a recarga dos cursos d'água fica comprometida, diante da remoção da vegetação.

Diante do exposto, torna-se evidente, a necessidade de articulação das políticas de uso da terra com os recursos hídricos, tendo em vista que os usos a que se destinam as áreas, refletem diretamente nos corpos hídricos, alterando as características quali-quantitativas das águas. Aliado a esse fato, a pressão sobre as nascentes aumenta com o avanço das atividades econômicas, a exemplo da agropecuária, através da remoção da vegetação das APPs para conversão destas áreas em pastagem ou agricultura, visando maior rentabilidade. Contudo, a disponibilidade de água é fator crucial para o desenvolvimento das atividades produtivas, sem a qual a produção, seja de animais ou vegetais, não se desenvolve.

\section{Conclusão}

Ao realizar o diagnóstico ambiental da microbacia do Córrego das Areias, por meio da análise de uso e ocupação do solo foi observado um aumento de $21,71 \%$ da área desmatada do ano de 2008 para 2019 na região. Fato esse que está ligado diretamente à expansão da agropecuária no local.

Em relação à qualidade da água, as concentrações encontradas para os parâmetros analisados atenderam ao que é estabelecido pela legislação vigente, considerando as características de um corpo hídrico de classe 2. Entretanto, a preservação do entorno dos recursos hídricos pode ser melhorada, visto que a análise do grau de preservação das nascentes revelou que nenhuma das nascentes avaliadas se enquadra na classificação ótimo ou boa.

Medidas de gestão que mitiguem os impactos ambientais devem ser introduzidas na área de estudo com o intuito de reduzir o aporte de nutrientes e sedimentos, e consequente aumento da qualidade da água. Assim como, de acordo com os resultados obtidos sobre o grau de preservação as nascentes classificadas como péssima ou ruim, torna-se imprescindível a revitalização destas, com medidas mitigadoras e projetos de revitalização voltados para esses ambientes, haja vista o papel fundamental exercido pela vegetação das APPs no entorno de nascentes para a disponibilidade hídrica da bacia.

\section{Agradecimentos}

O presente trabalho foi realizado com apoio da Coordenação de Aperfeiçoamento de Pessoal Nível Superior - Brasil (CAPES), agradecemos também ao Programa de Mestrado Profissional em Rede 
Nacional em Gestão e Regulação de Recursos Hídricos - ProfÁgua, Projeto CAPES/ANA AUXPE No. 2717/2015, pelo apoio técnico científico aportado até o momento.

Participação dos autores: ASB - concepção da pesquisa e delineamento, coleta e análise de dados, escrita e correções textuais ao longo do processo; NLRA - delineamento metodológico da pesquisa e estruturação textual, revisão e complementações dos resultados e discussões, revisão final do artigo.

Aprovação ética ou licenças de pesquisa: o presente estudo não possui licenças vinculadas a comitês de ética, considerando que o levantamento dos dados não utilizou experimentações com animais ou seres humanos ou necessitou de outro tipo de licença.

Disponibilidade dos dados: manuscrito desenvolvido a partir do trabalho de pesquisa de mestrado, com versão final depositada e disponível no repositório da Universidade Federal de Rondônia - UNIR (https://www.ri.unir.br/jspui/ browse $?$ type $=$ author\&value $=$ Betiolo $\% 2 \mathrm{C}+$ Aline + dos + Santos $)$.

Fomento: Programa de Mestrado Profissional em Rede Nacional em Gestão e Regulação dos Recursos Hídricos ProfÁgua, projeto CAPES/ANA AUXPE n 2717/2015; Universidade Federal de Rondônia - UNIR; Agência Nacional de Águas e Saneamento - ANA.

Conflito de Interesses: os autores informam não haver conflito de interesses.

\section{Referências}

Ana. Agência Nacional de Águas Brasil. 2017. MINISTÉRIO DO MEIO AMBIENTE. Conjuntura dos Recursos Hídricos no Brasil 2017. Relatório pleno / Agência Nacional de Águas. Brasília: ANA.

Aguiar CP, Peleja JRP, Sousa KNS. 2014. Qualidade da água em microbacias hidrográficas com agricultura nos municípios de Santarém e Belterra, Pará. Revista Árvore, 38(6):983-992. DOI: https://doi.org/10.1590/S0100-67622014000600003.

APHA. American Public Health Association. 2005. Standard methods for the examination of water and wastewater. 21th ed., Washington: APHA, EUA.

Braga B, Hespanhol I, Conejo JGL, Mierzwa JC, Barros MTL, Spence M, Porto M, Nucci N, Juliano N, Eiger S. 2005. Introdução à Engenharia Ambiental: Desenvolvimento Sustentável, 2. ed. São Paulo: Person Prentice Hall.

Brasil. Lei federal n¹2.651 DE 25 DE MAIO 2012. Dispõe sobre a proteção da vegetação nativa; altera as Leis nº 6.938, de 31 de agosto de 1981, 9.393, de 19 de dezembro de 1996, e 11.428, de 22 de dezembro de 2006; revoga as Leis nº 4.771, de 15 de setembro de 1965, e 7.754, de 14 de abril de 1989, e a Medida Provisória no 2.166-67, de 24 de agosto de 2001; e dá outras providências. Disponível em: http://www.planalto.gov.br/ccivil_03/_Ato2011-2014/2012/Lei/L12651.htm . Acesso em: 22 de out. 2019.

Butzke K. 2013. Avaliação limnológica de um igarapé impactado pela urbanização da cidade de Ji-Paraná (Rondônia): Igarapé Pintado. Ji-Paraná/RO: UNIR, 2013. Monografia (Bacharel em Engenharia Ambiental), Universidade Federal de Rondônia.

Conama. Resolução no 357 de 17 de março de 2005. Dispõe sobre a classificação e diretrizes ambientais para o enquadramento dos corpos de água superficiais, bem como estabelece as condições e padrões de lançamento de efluentes. Relator: Marina Silva. Diário Oficial da União, Brasília, 18 de março de 2005.

Costa CFG, Figueiredo RO, Santos I PO, Gerhard P, Pires CS, Barroso DFR, Costa FF, Brejão GL. 2017. Seleção de pontos de amostragem para monitoramento de qualidade de água em escala de microbacia na Amazônia. Amazônia em tempo: impactos do uso da terra em diferentes escalas. Belém: Embrapa Amazônia Oriental. 
Cunha DGF, Sabogal-Paz LP, Dodds WK. 2016. Land use influence on raw surface water quality and treatment costs for drinking supply in São Paulo State (Brazil). Ecological Engineering, 94(s/n):516-524. DOI: https://doi.org/10.1016/j. ecoleng.2016.06.063.

Damasceno MCS, Ribeiro HMC, Takiyama LR, Paula MT. 2015. Avaliação sazonal da qualidade das águas superficiais do Rio Amazonas na orla da cidade de Macapá, Amapá, Brasil. Revista Ambiente e Água, 10(3):598-613. DOI: https:// doi.org/10.4136/ambi-agua.1606.

Dias EC, Ferrari ALS, Schmidt RB, Silva F, Salvi JO, Salvi JS. 2019. Qualidade físico-química, microbiológica e a toxicidade de corpos hídricos do Parque Tecnológico Vandeci Rack em Ji-Paraná, Rondônia. South American Journal of Basic Education, Technical and Technological, 6(1): 282-296. https://periodicos.ufac.br/index.php/SAJEBTT/article/ view/2176

Esteves FA. 2011. Fundamentos de Limnologia. 3 ed. Rio de Janeiro: Interciência.

Ferreira RQS, Batista EC, Souza PA, Souza PB, Santos AF. 2015. Diagnóstico ambiental do córrego Mutuca, Gurupi - TO. Revista Verde, 10(4):08-12. https://doi.org/10.18378/rvads.v10i4.3146.

Filho OJV, Corsato LG, Quiessi JA, Kanno OY, Penteado RB, Arabori RM, Belorte LCC, Lima ME. 2016. Diagnóstico e reabilitação agroambiental de trecho de bacia hidrográfica por sensoriamento remoto e turbidez da água. Pesquisa Agropecuária Brasileira, 51(9):1099-1109. DOI: https://doi.org/10.1590/s0100-204x201600090000.

Franco GB, Betim LS, Marques EAG, Gomes RL, Chagas CS. 2012. Relação qualidade da água e fragilidade ambiental da Bacia do Rio Almada, Bahia. Revista Brasileira de Geociências, 42(1):114-127. https://doi.org/10.5327/Z037575362012000500010 .

Gholizadeh MH, Melesse AM, Reddi L. 2016. Water quality assessment and apportionment of pollution sources using APCS-MLR and PMF receptor modeling techniques in three major rivers of South Florida. Science Total Environment, 566-567(s/n):1552-1567. 10.1016/j.scitotenv.2016.06.046.

Gomes JB, Webler AD, Aguiar AG, Aguiar LJG, Nuñes MLA. 2015. Conversão de florestas tropicais em sistemas pecuários na Amazônia: quais as implicações no microclima da região? Revista Brasileira de Climatologia, 17(11):67-81. http://dx.doi.org/10.5380/abclima.v17i0.42879 .

Gomes PM, Melo C, Vale VS. 2005. Avaliação dos impactos ambientais em nascentes na cidade de Uberlândia-MG: análise macroscópica. Revista Sociedade e Natureza, 17(32):103-120. http://www.seer.ufu.br/index.php/sociedadenatureza/ article/view/9169.

Guimarães TMH, Pereira CE, Justo BB, Riquieri JC. 2019. Interferência do uso e ocupação do solo na qualidade da água em bacia hidrográfica com disponibilidade hídrica crítica. Geociências, 38(1):229-240. http://ppegeo.igc.usp.br/index. php/GEOSP/article/view/13378/12971.

IBGE. Instituto Brasileiro de Geografia e Estatística. Disponível em: https://cidades.ibge.gov.br/brasil/ro/novabrasilandia-doeste/pesquisa/15/11863. Acesso em: 15 de nov. 2019.

Ikematsu P, Franqueiro N, Tavares TLS, Faccini LG, Terrell D, Cavani ACM, Longo MHC. 2017. Aspectos técnicos para priorização de recursos em recuperação e conservação de nascentes. Revista Águas Subterrâneas, 1(s/n):1-18. DOI:10.14295/ras.v0i0.28740.

INPE. Instituto Nacional de Pesquisas Espaciais. Catálogo de imagens. Disponível em: http://www.dgi.inpe.br/CDSR/. Acesso em: 06 de set. 2019a.

INPE. Instituto Nacional de Pesquisas Espaciais. Programa Queimadas. Disponível em: http://queimadas.dgi.inpe.br/ queimadas/portal-static/estatisticas_estados/. Acesso em: 15 nov. 2019b.

Javadi S, Moghaddam HK, Roozbahani R. 2019. Determining springs protection areas by combining an analytical model and vulnerability index. Catena, 182(s/n). DOI: https://doi.org/10.1016/j.catena.2019.104167. 
Leal MS, Tonello KC, Dias HC, Mingoti R. 2017. Caracterização hidroambiental de nascentes. Revista Ambiente e Água, 12(1):146-155. DOI:10.4136/ambi-agua.1909.

Machado TCE, Campos MCC, Pagani CHP, Cunha JM, Soares MDR. 2017. Avaliação do uso e ocupação das áreas de preservação permanente nos anos de 2008 e 2013 na zona urbana de Humaitá, Amazonas. Revista da Universidade Vale do Rio Verde, 15(2):744-750. DOI: http://dx.doi.org/10.5892/ruvrd.v15i2.3017 .

Marmontel CVF, Lucas-Borja ME, Rodrigues VA, Zema DA. 2018. Effects of land use and sampling distance on water quality in tropical headwater springs (Pimenta creek, São Paulo State, Brazil). Science of the Total Environment, 622623(s/n):690-701. DOI: https://doi.org/10.1016/j.scitotenv.2017.12.011 .

Marsaro CCS, Valentini CMA, Faria RAPG, Abido AS. 2017. Análise físico-química e percepção ambiental do córrego Engole Cobra no município de Cuiabá Cuiabá-MT. Revista Internacional de Ciências, 7(1):100-122. DOI:10.12957/ ric.2017.26135.

Matias MIAS, Santos JVS, Freitas RMO, Matias LCS. 2018. Qualidade de corpos hídricos no extremo Sul da Bahia. Revista Verde de Agroecologia e Desenvolvimento Sustentável, 13(2):235-240. DOI:10.18378/rvads.v13i2.5467.

Medeiros AC, Faial KRF, Faial KCF, Lopes IDS, Lima MO, Guimarães RM, Mendonça NM. 2017. Quality index of the surface water of Amazonian rivers in industrial areas in Pará, Brazil. Marine Pollution Bulletin, 123(1-2):156-164. DOI: https://doi.org/10.1016/j.marpolbul.2017.09.002.

Mello K, Valente RA, Randhir TO, Santos ACA, Vettorazzi CA. 2018. Effects of land use and land cover on water quality of low-order streams in Southeastern Brazil: Watershed versus riparian zone. Catena, 167(s/n):130-138. DOI: https:// doi.org/10.1016/j.catena.2018.04.027.

Menezes JP, Bittencourt RP, Farias MS, Bello IP, Fia R, Oliveira LFC. 2016. Relação entre padrões de uso e ocupação do solo e qualidade da água em uma bacia hidrográfica urbana. Engenharia Sanitária e Ambiental, 21(3):519-534. DOI: http://dx.doi.org/10.1590/S1413-41522016145405.

Moraes GF, Lima EBNR, Ferrarez EM. 2018. Physiographic Characterization and Land use and Occupation of the Urban Microbasins of the City of Cuiabá-MT. E\&S - Engineering and Science, 2(7):42-53. DOI: 10.18607/ES201876822.

Moura V, Silva PJC, Rosell ECF, Alves WW. 2017. A. Análise multitemporal do uso e ocupação do solo em Áreas de Preservação Permanente (APP) na bacia do rio Piranha, São Miguel do Guaporé, Rondônia (RO), Brasil. Revista Geográfica Venezolana, 58(2):414-429. https://www.redalyc.org/jatsRepo/3477/347753793010/movil/index.html.

Negri-Sakata V, Kimura IY. 2018. Nascentes Urbanas de Goioerê: diagnóstico ambiental. Geografia (Londrina), 27(2):185205. DOI:10.5433/2447-1747.2018v27n2p185.

Oliveira LF, Oliveira BOS, Lima LB. 2018. Avaliação da qualidade da água de três córregos na área urbana de Humaitá AM. Revista da Ciências Ambientais, 12(3):25-33. DOI:10.18316/rca.v12i3.3606.

Oliveira TMBF, Di-Souza L, Castro SSL. 2009. Dinâmica da série nitrogenada nas águas da bacia hidrográfica Apodi/ Mossoró - RN - Brasil. Eclética Química, 34(3):17-26. https://doi.org/10.1590/S0100-46702009000300002.

Pereira BWF, Maciel MNM, Oliveira FA, Alves MAMS, Ribeiro AM, Ferreira BM, Ribeiro EGP. 2016. Uso da terra e degradação na qualidade da água na bacia hidrográfica do rio Peixe-Boi, PA, Brasil. Revista Ambiente e Água, 11(2):472485. DOI: doi:10.4136/ambi-agua.1802.

Pereira MR. 2016. Uso da luminescência como ferramenta de detecção de oxigênio dissolvido para verificação da qualidade de água bruta superficial. Originalmente apresentado como Projeto tecnológico, graduação em Química Industrial, Universidade Federal do Rio Grande do Sul.

Pessi DD, Ereio PKB, Alves GBM, Martarello AP, Loverde-Oliveira SM. 2018. Qualidade da Cobertura Vegetal em Áreas de Preservação Permanente de Nascentes. Anuário do Instituto de Geociências - UFRJ, 41(3):270-280. http://dx.doi. org/10.11137/2018_3_270_280. 
Pieroni JP, Rodrigues-Branco KG, Dias GRV, Ferreira GC. 2019. Avaliação do estado de conservação de nascentes em microbacias hidrográficas. Geociências, 38(1):185-193. http://www.ppegeo.igc.usp.br/index.php/GEOSP/article/ view/13374.

Pinto MA, Rodrigues VMV, Souza BS, Maria YR, Felici EM, Balarim NG, Fuzeto IMR, Hespanhol RM, Guaberto LM. 2019. Diagnóstico ambiental dos afluentes do Córrego do Lajeado no município de Pirapozinho - SP. Colloquium Exactarum, 11(4):104-121. 10.5747/ce.2019.v11.n4.e300.

Rocha IL, Salomão LC, Iwata BF, Souza JAR, Moreira DA. 2019. Qualidade ambiental das nascentes do Rio Paraim, extremo sul do Piauí. Revista Ibero Americana de Ciências Ambientais, 10(3):385-399. DOI: http://doi.org/10.6008/ CBPC2179-6858.2019.003.0032.

Rocha VM, Correia FWS, Silva PRT, Gomes WB, Vergasta LA, Moura RG, Trindade MSP, Pedrosa AL, Silva JJS. 2017. Reciclagem de Precipitação na Bacia Amazônica: O Papel do Transporte de Umidade e da Evapotranspiração da Superfície. Revista Brasileira de Meteorologia, 32(3):387-398. https://doi.org/10.1590/0102-77863230006.

Santos A. 2012. Avaliação da capacidade de autodepuração do rio Ji-Paraná (Rondônia), através da curva de depleção do oxigênio dissolvido. UNIR, 2012. Monografia (Bacharel em Engenharia Ambiental), Universidade Federal de Rondônia.

Santos CL, Souza AS, Vital SRO, Girão O, Wanderley LSA. 2016. Impactos da urbanização em bacias hidrográficas: o caso da bacia do Rio Jaguaribe, Cidade de João Pessoas/PB. Revista de Geociências do Nordeste, 2(n. especial):1025-1033.

Santos LCL, Brito GHM. 2018. Delimitação das áreas de preservação permanente na bacia hidrográfica do Rio dos Patos, GO e identificação dos conflitos de uso de solo. Ipê Agronomic Journal, 2(1):53-60.

Silva COF, Gouveia D. 2019. Avaliação da qualidade ambiental de corpos hídricos urbanos utilizando análise multivariada. INTERAÇÕES, 20(3):947-958. DOI: https://doi.org/10.20435/inter.v0i0.1832.

Silva TGN, Gama RC, Teixeira LG, Santos GR, Souza RM, Souza PB. 2018. Diagnóstico ambiental de uma área de proteção permanente (APP), Formoso do Araguaia - TO. Revista da Universidade Vale do Rio Verde, 16(2):1-10. DOI: http://dx.doi.org/10.5892/ruvrd.v16i2.4619.

Torres IA, Silva TMF, Rodrigues LS, Silva IJ, Costa TA, Soto-Blanco B, Melo MM. 2017. Avaliação físico-química de amostras de água, sedimento e mata ciliar de uma piscicultura localizada em área agroindustrial à margem do Ribeirão da Mata (MG). Engenharia Sanitária e Ambiental, 22(4):773-780. DOI: 10.1590/S1413-41522017110861.

Watanabe M, Oliveira FA, Nunes DD, Nunes ACS, Cavalcante MMA, Aguiar TC. 2018. Análise do impacto do desmatamento no aporte sedimentar de bacias pareadas na Amazônia ocidental: bacias do Rio Mutum-Paraná, Rondônia (Brasil). Revista Brasileira de Geomorfologia, 19(3):601-615. DOI:10.20502/rbg.v19i3.1287. 